УДК 378.096

DOI 10.31483/R-21427

\title{
O.B. Григораи
}

\section{ОСОБЕННОСТИ ОЦЕНКИ КАЧЕСТВА ОБРАЗОВАНИЯ ВЫПУСКНИКОВ ВУЗОВ ТЕХНИЧЕСКИХ СПЕЦИАЛЬНОСТЕЙ}

Аннотация: в данной работе определён основной инструментарий и условия эффективной реализации оченочных средств для оченки качества образования выпускников технических вузов (факультетов). Автором раскрыты основные подходы к понятию качества образования и его очениванию, даны определения понятиям «качество подготовки» и «качество образования» выпускников вузов. Предлагаются аналитические выражения для расчётов коэффициента уровня подготовки студентов по результатам семестра и коэффициента качества образования за период обучения, включающий показатель качества подготовки, оценки по практикам и выпускным квалификацчионным работам, а также балль трудового потенцчиала.

Ключевые слова: качество подготовки, качество образования, оценочные средства, компетентностный подход, балльно-рейтинговая система оценки.

\section{FEATURES OF EDUCATION QUALITY EVALUATION OF TECHNICAL UNIVERSITIES GRADUATES}

Abstract: the main tools and conditions for the effective implementation of evaluation tools for assessing the education quality of technical universities (faculties) graduates are defined in this paper. The author reveals the main approaches to the notion of the quality of education and its evaluation, defines the concepts of "quality of preparation" and "quality of education" of graduates of universities. Analytical expressions are proposed for calculating the coefficient of student's preparation level based on the semester results and the quality of education during the training period, including the indicator of the quality of training, assessment of practices and final qualification papers, and the scores of the labor potential. 
Keywords: quality of preparation, quality of education, assessment tools, competence approach, rating system of evaluation.

Оценка качества образования студентов является одной из важнейших составляющих в организации образовательного процесса в вузе. При разработке оценочных средств важно учитывать также, что научно-педагогическая деятельность - творческий её вид, и здесь возможно применять неординарные методики оценки. Определение точных критериев и показателей оценки качества образования студентов, представляется крайне сложным, но вместе с тем актуальным $[3$, c. $32-33 ; 5$, c. $21-22]$.

Основные мировые тенденции в области оценки качества образования:

1) качество рассматривается с позиций его соответствия требованиям работодателей;

2) комплексное обеспечение и управление качеством образования путем создания единых стандартов;

3) применение внутренней и внешней системы оценки качества;

4) использование оценки качества образования выпускников как средства отчётности, способствующего развитию образовательного учреждения;

5) выделение показателей, характеризующих разные уровни образовательной системы (национальный, региональный, уровень образовательного учреждения, уровень обучающегося), а также показателей, характеризующих инвестиции в образование, образовательный процесс и образовательные достижения.

Анализируя основные тенденции в области оценки качества в нашей стране и за рубежом, сегодня актуальным является компетентностный подход к оценке качества образования, который предполагает оценку уровня владения студентом совокупностью компетенций, степенью готовности к их применению в профессиональной деятельности [4, с. 49].

Внедрение компетентностного подхода позволит в значительной мере peaлизовать лично- и практико-ориентированный подходы в образовательном процессе, поскольку выделение компетенций в содержании учебных дисциплин определяет ориентиры в отборе тех знаний и умений, которые будут 
востребованы в профессиональной деятельности обучающихся. Это достоинство метода. Компетентностный подход в образовательной деятельности предполагает оперативную реакцию на потребности работодателей: последние участвуют в формировании компетенций, а образовательные учреждения осуществляют подготовку необходимых специалистов.

Востребованный в настоящее время компетентностный подход в оценке качества образования выпускников вузов позволяет более продуктивно выстраивать отношения между образовательными учреждениями и работодателями. При этом образовательные технологии рассматриваются как способ формирования компетенций, а оценочные средства - как инструмент проверки их качества.

На компетентностный подход в оценке качества образования выпускников вузов опираются и последние ФГОС. Однако методических указаний по формированию базы оценочных средств для оценки компетенций выпускников вузов Министерством науки и высшего образования РФ не разработано. Каждый вуз решает задачу самостоятельно, при этом, как правило, не учитываются особенности специализации подготовки выпускников в соответствии с образовательной программой.

Исходя из разнообразия подходов к оценке качества подготовки и образования выпускников технических вузов (факультетов) предлагается комплексный системно-компетентностный подход к разработке оценочных средств.

В настоящее время деятельность образовательной системы должна быть направлена на развитие экономики страны ускоренными темпами. Поэтому основные стратегические цели и задачи системы образования должны сводиться к постоянному улучшению качества подготовки студентов технических и технологических вузов (факультетов), от которых главным образом зависит уровень экономического развития государства [1, с. 9, с. 1390].

Важными инструментами и условиями при реализации оценочных средств для технических специальностей являются:

- балльно-рейтинговая система оценки качества подготовки студентов в отчетный период (семестр, учебный год, период обучения). Эта система 
мотивирует студентов на регулярную работу, повышает их интерес к изучению учебных дисциплин и дух состязательности, направленный на улучшение результатов, что в комплексе способствует повышению качества образования выпускников вузов. Результаты балльно-рейтинговой системы оценки студентов являются важным мотивационным рычагом в образовательной деятельности профессорско-преподавательского состава, способствующего совершенствованию их профессиональной квалификации, а также учебно-методического и материально-технического обеспечения дисциплин [2, с. 1195-1196];

- тестовые задания позволяют оперативно получать информацию о результатах освоения ОП, об эффективности работы преподавателей. В общем случае они выполняют две функции: самоконтроль (индивидуальная проверка уровня знаний) и итоговая проверка (контрольная проверка преподавателя), что способствует повышению эффективности образовательного процесса в рамках его модернизации;

- создание условий, мотивирующчх повыщение качества знаний студенmов, за счёт внедрения инновационных технологий в учебный процесс, включающих активные и интерактивные методы обучения, занятия, проводимые студентами под руководством преподавателя, досрочную сдачу экзаменов с «автоматическим» выставлением оценок «5» или «4», если средний балл текущих оценок в семестре превышал 4,5 и 4,0 соответственно, право выбора руководителя выпускной квалификационной работы и т. п.

В области технического образования в силу его особенностей при разработке оценочных средств необходимо оценивать как учебный (знания, умения и навыки), так и трудовой потенциал в рамках уровня сформированности компетенций, направленных на развитие творческого и абстрактного мышления, способностей к анализу и синтезу, изучению и эксплуатации устройств, оборудования, систем и технологических процессов [1, с. 1391-1392].

Оценка качества подготовки студентов должна проводиться по каждой дисциплине и по результатам сдачи экзаменов (зачётов) каждого семестра обучения. 
После анализа её результатов судят о необходимости модернизации образовательного процесса.

Коэффициент качества подготовки студентов по дисциплине определяется по формуле (Патент РФ №2636019. Способ организации и ведения мониторинга качества учебной работы преподавателей. О.В. Григораш, А.И. Трубилин):

$$
K \Pi_{\text {д }}=\frac{1}{3}\left(C Б_{T K}+O_{\ni(3)}+\frac{\Pi_{K A \Psi}}{20}\right),
$$

где $C Б_{T K}-$ средний балл оценок, полученных на экзамене (зачёте), в том числе по защите курсовых работ (проектов); $O_{\ni(3)}$ - общая оценка группы, полученная на экзамене (зачёте), определяется с учетом показателей пороговых значений; $\Pi_{K A ч}$ - показатель качества обучения, отражающий процент студентов, получивших оценки «4» и «5».

Необходимость введения трёх показателей для определения качества подготовки студентов обусловлена следующими причинами: невозможностью определения только по одному среднему баллу, сколько студентов изучили дисциплину, к примеру, на оценку «5», а сколько вообще не усвоили, т. е. получили оценку «2»; при одном и том же среднем балле может быть разное количество отличников и студентов, получивших оценки «2», и может их вообще не быть.

Коэффициент качества подготовки студентов (учебный потенциал) по результатам сессии:

$$
K \Pi_{C}=\frac{1}{d} \sum_{n=1}^{d} K \Pi_{\not n},
$$

где $d$ - общее количество учебных дисциплин.

Коэффициент качества образования выпускников вуза (уровня сформированности компетенций) предлагается определять по формуле

$$
K O_{B}=\frac{1}{4}\left(\frac{1}{c} \sum_{i=1}^{c} K \Pi_{C i}+\frac{1}{p} \sum_{j=1}^{p} C S_{\Pi j}+\frac{1}{m} \sum_{k=1}^{m} O_{B K P k}+\frac{1}{m} \sum_{k=1}^{m} S_{T \Pi k}\right),
$$

где $c$ и $p$ - общее количество сессий и практик, соответственно; $m$ - общее количество студентов; $O_{B K P}-$ оценка студента по защите выпускной квалификационной работы; $5_{T п}-$ баллы трудового потенциала студента, которые определяются по формуле 


$$
Б_{T \Pi}=P_{\text {ниР }}+H+C+\Pi-B,
$$

где $P_{H и P}-$ результаты научно-исследовательской работы:

$$
P_{\text {НИР }}=Б_{\text {ПА }}+Б_{\text {КВО }}+Б_{\text {ГХД }},
$$

где $Б_{П А}-$ баллы за публикационную активность; $5_{K B O}-$ баллы за участие в

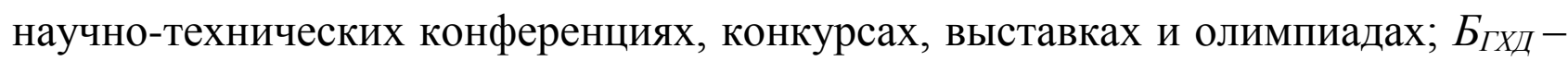
баллы за участие в грантах и хоздоговорных работах; $H$ - баллы, учитывающие награды за достижения в учёбе, научно-исследовательской и общественной работе, а также по результатам участия в спортивных и культурно-массовых мероприятиях; $C$ - баллы, учитывающие стипендии международного, федерального, регионального или вузовского уровня; П- баллы, учитывающие поощрения (благодарности) за достижения в учёбе, научно-исследовательской и общественной работе; $B$ - баллы, учитывающие взыскания за низкие результаты в учёбе, пропуски занятий, нарушения Устава вуза и другие неправомерные действия.

Поскольку в нашей стране принята 5-балльная шкала оценок, то коэффициент, определяющий баллы по трудовому потенциалу $5_{T \Pi}$ в формуле (4) должен иметь минимальное значение «2», а максимальное (пороговое) - «5». Исследования, проводившиеся более 10 лет [6], позволили установить для формулы (4) нормативы балловых показателей.

Таким образом, на основе анализа результатов исследований отечественных и зарубежных учёных раскрыты основные подходы к понятию качества образования и его оцениванию, даны определения понятиям «качество подготовки» и «качество образования» выпускников вузов. Предложены аналитические выражения для расчетов коэффициентов подготовки и качества образования выпускников вузов.

\section{Сиисок литературы}

1. Бедерханова В.П. Высшее техническое образование: особенности и перспективы развития / В.П. Бедерханова // Политематический сетевой электронный научный журнал Кубанского государственного аграрного университета (Научный журнал КубГАУ). - Краснодар: КубГАУ, 2017. - №08 (132). - С. 13891399. 
2. Ершова О.В. Рейтинговая система оценки качества образования как средство мотивации студентов в системе профессиональной подготовки / О.В. Ершова // Международный журнал прикладных и фундаментальных исследований. - 2016. - №11. - С. 1194-1197.

3. Звонников В.И. Современные подходы к оцениванию качества результатов высшего образования / В.И. Звонников, М.Б. Челышкова // Педагогические измерения. - 2016. - №1. - С. 32-38.

4. Леушин И.О. Некоторые вопросы разработки и реализации образовательных программ в техническом вузе / И.О. Леушин, И.В. Леушина // Высшее образование в России. - 2016. - №4. - С. 49-53.

5. Шихов Ю.А. Проблема измеримости образовательных стандартов высшего профессионального образования / Ю.А. Шихов, О.Ф. Шихова, А.А. Касаткин // Образование и наука. - 2016. - №1 (130). - С. 21-33.

6. Григораш О.В. Комплексная оценка качества подготовки студентов и эффективности деятельности кафедры / О.В. Григораш, А.И. Трубилин. - Краснодар: КубГАУ, 2017. - С. 121-123.

\section{References}

1. Bederkhanova, V. P. (2017). Vysshee tekhnicheskoe obrazovanie: osobennosti i perspektivy razvitiia. Politematicheskii setevoi elektronnyi nauchnyi zhurnal Kubanskogo gosudarstvennogo agrarnogo universiteta (Nauchnyi zhurnal KubGAU), 08 (132), 1389-1399. Krasnodar: KubGAU.

2. Ershova, O. V. (2016). Reitingovaia sistema otsenki kachestva obrazovaniia kak sredstvo motivatsii studentov $\mathrm{v}$ sisteme professional'noi podgotovki. Mezhdunarodnyi zhurnal prikladnykh i fundamental'nykh issledovanii, 11, 11941197.

3. Zvonnikov, V. I., \& Chelyshkova, M. B. (2016). Sovremennye podkhody k otsenivaniiu kachestva rezul'tatov vysshego obrazovaniia. Pedagogicheskie izmereniia, 1, 32-38. 
4. Leushin, I. O., \& Leushina, I. V. (2016). Nekotorye voprosy razrabotki i realizatsii obrazovatel'nykh programm $\mathrm{v}$ tekhnicheskom vuze. Vysshee obrazovanie $\mathrm{v}$ Rossii, 4, 49-53.

5. Shikhov, Iu. A., Shikhova, O. F., \& Kasatkin, A. A. (2016). Problema izmerimosti obrazovatel'nykh standartov vysshego professional'nogo obrazovaniia. Obrazovanie i nauka, 1 (130), 21-33.

6. Grigorash, O. V., \& Trubilin, A. I. (2017). Kompleksnaia otsenka kachestva podgotovki studentov i effektivnosti deiatel'nosti kafedry., 121-123. Krasnodar: KubGAU.

Григораш Олег Владимирович - д-р техн. наук, профессор, заведующий кафедрой электротехники, теплотехники и возобновляемых источников энергии ФГБОУ ВО «Кубанский государственный аграрный университет им. И.Т. Трубилина», Россия, Краснодар.

Grigorash Oleg Vladimirovich - doctor of engineering sciences, professor, head of the department of electrical engineering, heat engineering and renewable energy sources at the Kuban State Agrarian University, Russia, Krasnodar. 